\title{
Rabaska
}

Revue d'ethnologie de l'Amérique française

\section{LI, SHENWEN. Stratégies missionnaires des jésuites français en Nouvelle-France et en Chine au XVII siècle. Québec, Les Presses de l'Université Laval; et Paris, L'Harmattan, " collection Intercultures », 2001, 379 p. ISBN 2-7637-7792-9}

\section{Jean Simard}

Volume 2, 2004

URI : https://id.erudit.org/iderudit/201671ar

DOI : https://doi.org/10.7202/201671ar

Aller au sommaire du numéro

Éditeur(s)

Société québécoise d'ethnologie

ISSN

1703-7433 (imprimé)

1916-7350 (numérique)

Découvrir la revue

Citer ce compte rendu

Simard, J. (2004). Compte rendu de [LI, SHENWEN. Stratégies missionnaires des jésuites français en Nouvelle-France et en Chine au XVII siècle. Québec, Les

Presses de l'Université Laval; et Paris, L'Harmattan, " collection Intercultures ", 2001, 379 p. ISBN 2-7637-7792-9]. Rabaska, 2, 225-227.

https://doi.org/10.7202/201671ar d'utilisation que vous pouvez consulter en ligne. 
Li, SHenwen. Stratégies missionnaires des jésuites français en NouvelleFrance et en Chine au XVII' siècle. Québec, Les Presses de l'Université Laval; et Paris, L'Harmattan, « collection Intercultures », 2001, 379 p. ISBN 2-7637-7792-9.

Le rôle tenu par les jésuites français dans l'évangélisation des Amérindiens du Canada est bien connu. Il a fait le sujet de travaux édifiants à la fin du $\mathrm{XIX}^{\mathrm{e}}$ et pendant la première moitié du $\mathrm{XX}^{\mathrm{e}}$ siècle et ensuite $\mathrm{d}^{\text {'analyses plus }}$ critiques qui montrent les conséquences néfastes de cette « épopée mystique » pour la spiritualité, l'équilibre social et la santé des sociétés évangélisées. L'on connaît cependant beaucoup moins l'histoire de ces mêmes jésuites français envoyés en Chine à la même époque, c'est-à-dire aux XVII ${ }^{e}$ et XVIII ${ }^{e}$ siècles, et qui avaient aussi pour tâche de modifier un système et des comportements religieux, mais ceux-là plus anciens que le christianisme luimême et ancrés dans une société complexe et raffinée, au regard même des Européens de cette époque. Le livre de Shenwen $\mathrm{Li}$ - issu d'une thèse de doctorat en histoire présentée à l'université Laval en 1998 - nous raconte ces deux expériences d'évangélisation en les comparant principalement du point de vue des stratégies utilisées par les missionnaires pour convertir des peuples qui étaient aux antipodes du développement.

La mission canadienne s'étend principalement de 1632 à 1701, de l'arrivée de Paul Le Jeune à la signature de la Grande Paix de Montréal. Celle de Chine va de 1656 à 1717, la première date marquant le début d'une migration continue de jésuites français, la seconde étant la déclaration d'interdiction du christianisme dans l'empire. D'où le XVII siècle donné au titre de l'ouvrage. Il n'est pas habituel pour un historien de considérer une 
période aussi longue et l'auteur s'en explique en précisant que le recours à la longue durée s'imposait à lui dans la mesure où les phénomènes de transformation culturelle et les processus d'adaptation s'étalent sur de longues périodes. Et, autre chose inhabituelle aussi, Li considère l'histoire « comme un vaste terrain ethnologique, un lieu d'observation des pratiques interculturelles à un moment donné du passé » (p. 17), perspective que lui a soumise son patron de thèse Laurier Turgeon. De quoi certainement faire frémir d'horreur les gens de la profession qui n'ont jamais imaginé que l'histoire pouvait être vue comme un vaste champ d'observation au service d'une autre discipline. Ajoutons que les sources sur les missions canadiennes et chinoises sont particulièrement comparables du fait que les jésuites écrivaient et publiaient beaucoup. Par ailleurs les témoignages sur les missions de la Nouvelle-France sont à sens unique étant donné que les Amérindiens n'écrivaient pas et cette lacune obligée prive l'auteur de nous présenter le tableau complet de la situation de ce côté-ci. En revanche il se reprend avec la mission chinoise puisqu'il met à contribution les divers rapports et correspondances entre jésuites et lettrés de « l'Empire du Milieu » qui mettent bien en évidence les réactions, bonnes et mauvaises, à l'évangélisation.

Le livre s'ouvre sur un chapitre qui rappelle les objectifs qu'avait saint Ignace de Loyola en fondant la Compagnie de Jésus et les méthodes qu'il privilégiait pour contrer la réforme protestante et donner un nouveau souffle à l'Église de Rome qui avait déjà perdu en Europe près de la moitié de ses membres. Les candidats aux lointaines missions recevaient une formation commune fondée sur les mêmes règles d'obéissance et d'adaptation au changement mais aussi sur le même désir de mourir martyr pour leur foi. Les jésuites qui sont devenus missionnaires au Canada et en Chine ont pour la plupart enseigné ou étudié au même collège de La Flèche, où ils se côtoyaient, lisaient les mêmes récits de conversion et brûlaient d'envie de partir à leur tour. La suite décrit la rencontre des jésuites avec les Amérindiens de la Nouvelle-France, perçus comme des « sauvages » qu'ils devaient remodeler à l'européenne, puis des Chinois, vus comme des « civilisés » avec lesquels il fallait plutôt transiger. Cette étude traite tout à la fois des cultures française, amérindienne et chinoise, dans leur réalité objective comme dans la perception que chacune avait de l'autre à l'époque des premiers contacts, et des jésuites eux-mêmes, soldats du Christ pour qui presque tous les moyens sont bons pour transformer en vrais chrétiens des peuples qui, redisons-le, sont aux antipodes du développement sur tous les plans. Elle compare dans le détail les moyens utilisés par les disciples de saint Ignace qui se faisaient savants et sinophiles pour les lettrés chinois, puis magiciens et autoritaires pour les autochtones d'Amérique. Ici les nouveaux convertis portaient le costume des Français, là-bas les jésuites s'habillaient à la chinoise. Là-bas, ils tentaient 
de concilier les principes du confucianisme avec la tradition chrétienne alors qu'ici ils dévalorisaient la spiritualité animiste en vue de la remplacer. À l'empereur et aux lettrés chinois, les jésuites offraient des cadeaux de qualité, comme des instruments de haute précision utilisés par les mathématiciens et les astronomes de l'Académie royale des sciences, aux Amérindiens ils offraient plutôt de menus objets comme des perles de verre, des fioles et des pierres d'aimant. Le résultat net de tous ces efforts ? Les jésuites baptisent $30 \%$ de la population amérindienne, peut-être 18000 , la plupart d'ailleurs au seuil de la mort, les formules imaginées pour les sédentariser et les convertir (séminaire et réduction) finissent par échouer. En Chine ils font 300000 convertis mais qui ne représentent que $0,2 \%$ de la population.

Ce livre ajoute un très beau chapitre à l'étude des missions de la Compagnie de Jésus mais, plus encore, il contribue à poser les premières assises de l'interculturel dans l'ethnologie du Québec. Souhaitons maintenant qu'un émule de Shenwen Li poursuive sa démarche et étende le domaine qui émerge à l'Europe catholique dans ses relations avec toutes les Amériques. Pour qui observe le Mexique par exemple, l'expérience de l'Église espagnole auprès des Mayas, capables de calculer avec grande précision le mouvement des corps célestes, ou encore des Aztèques qui ont pu construire une ville (Mexico) sur des marécages sans que ses 200000 habitants n'aient jamais les pieds dans l'eau, offre un terrain de comparaison exceptionnel. On y découvrirait probablement que les Indiens d'Amérique ont eu, du nord au sud, un même grand attrait pour les images, ce que, à l'évidence, les Espagnols ont utilisé sans aucune retenue.

JeAN Simard

Société québécoise d'ethnologie, Québec 